\title{
Computation of Biomass Combustion Characteristic and Kinetic Parameters by using Thermogravimetric Analysis
}

\author{
Wanwisa Rukthong ${ }^{1}$, Phattharanid Thanatawee ${ }^{1}$, Sasithorn Sunphorka ${ }^{1}$, \\ Pornpote Piumsomboon ${ }^{1,2}$, and Benjapon Chalermsinsuwan ${ }^{1,2, *}$ \\ 1 Fuels Research Center, Department of Chemical Technology, Faculty of Science, Chulalongkorn \\ University, 254 Phayathai Road, Patumwan, Bangkok 10330, Thailand \\ 2 Center of Excellence on Petrochemical and Material Technology, Chulalongkorn University, 254 \\ Phayathai Road, Patumwan, Bangkok 10330, Thailand \\ *E-mail: benjapon.c@chula.ac.th (Corresponding author)
}

\begin{abstract}
In this study, the response surface methodology and simplex-lattice design were applied to investigate the effect of biomass constituents on the kinetics of biomass combustion, important information for process design. The synthetic biomass made from pure cellulose, xylan and Organosolv lignin was used instead of real biomass for this purpose. The combustion process was employed using thermogravimetric analyzer. The results obtained from three different kinetic models including Kissinger-Akahira-Sunose, Ozawa-Flynn-Wall and Analytical Method were provided and compared. According to the analysis of variances (ANOVA), the higher cellulose and hemicellulose fraction provided greater activation energy and frequency factor. The proposed regression models with high $\mathrm{R}^{2}$ coefficient indicated that the predicted kinetic values and experimental data agreed very well. The contour plots generated from the proposed models were also provided in this study. They were used to observe the influence of biomass components on each kinetic parameter.
\end{abstract}

Keywords: Biomass, combustion, kinetic parameters, response surface methodology, TGA.

ENGINEERING JOURNAL Volume 19 Issue 2

Received 5 August 2014

Accepted 24 November 2014

Published 30 April 2015

Online at http://www.engj.org/

DOI:10.4186/ej.2015.19.2.41 


\section{Introduction}

The energy crisis has been issued and driven to research and utilize renewable resources. Biomass is considered for energy purposes by partially substitution of coal and petroleum. The thermochemical conversion processes of biomass including pyrolysis, combustion and gasification are alternative ways for biomass conversion. Oxidation is the major technology for bioenergy production [1]. The biomass oxidation involves several simultaneous physical and chemical processes such as elimination of water, the release of volatile, fixed carbon production, dissociation of volatile matter into oil and gases, oxidation of produced gases and fixed carbon, and decarbonation [2]. However, the complexity in reaction mechanism and biomass structure leads to difficulty in prediction of behavior of biomass oxidation. The understanding in biomass oxidation process and estimation of kinetic parameters such as the activation energy, frequency factor and reaction order is very important for simulation and optimization of reactors. The appropriate models that achieve a better understanding of this process have been studied and many literatures proposed the mathematical models for kinetic modeling and decomposition profile of biomass oxidation [3-7].

Among the lab-scale apparatus, the thermogravimetric analysis (TGA) is a common technique to study the fundamental kinetic characteristics of biomass pyrolysis and oxidation. Therefore, some of literatures studied the behavior of biomass combustion in TGA. The kinetic parameters were then obtained from TGA data by using various methods, such as analytical, differential, and integral methods [8-12]. Chen et al. investigated the combustion behavior of Chlorella vulgaris microalgae by using TGA in $\mathrm{O}_{2} / \mathrm{N}_{2}$ atmospheres [11]. The activation energy of microalgae combustion at different oxygen concentration was calculated by iso-conversional methods including Ozawa-Flynn-Wall (OFW) and Kissinger-Akahira-Sunose (KAS) methods. By using FWO and KAS, the values of activation energy were $134.03-241.04 \mathrm{~kJ} / \mathrm{mol}^{-1}$ and $134.53-242.33 \mathrm{~kJ} / \mathrm{mol}^{-1}$, respectively. Idris et al. calculated the kinetic values for the oxidation of palm kernel shell, palm mesocarp fibre and empty fruit bunches from TGA data using model-free kinetics developed by Vyazovkin and Sbirrazzuoli [12]. The average apparent activation energies for the combustion of these biomasses were 139,118 and $105 \mathrm{~kJ} / \mathrm{mol}$, respectively.

The prediction of kinetic parameters from biomass composition has also been focused in many literatures [8, 13-15]. López-González et al. investigated the combustion characteristics of biomass main components and three real biomasses [13]. The authors reported that the biomass oxidation behavior was influenced by its composition. Biomass with higher cellulose content shifted the devolatilization stage to lower temperatures and increased the decomposition rate whilst the lignin content affect the behavior of char oxidation stage. Conesa and Domene studied the decomposition of five biomasses in TGA and proposed global kinetic models [15]. The proposed model, derived under the assumption of simultaneous parallel decomposition reactions of three different organic fractions, provided a good agreement between predicted values and experimental values. From this point of view, the development of simplified kinetic model which can potentially predict the combustion behavior and kinetic values is still attractive.

Recently, the statistical techniques have been applied to investigate the relationship between input parameters and desired responses. The process information involving physical or chemical mechanism does not required in these techniques. The response surface methodology (RSM) is one of the mathematical and statistical techniques. It was commonly used to evaluate the effect of the individual factors on the desired output [16-20]. Among the several experimental design methods, the simplex-lattice design (SLD) was chosen to investigate the influence of correlated three factors. Therefore, it is suitable for applying to biomass process since the biomass has three main compositions: cellulose, hemicellulose and lignin (under dry, ash-free basis). In case of pyrolysis, Liu et al. used SLD to determine the interaction between the biomass components [18] whilst Yang et al. also employed the SLD to examine the relationship between biomass composition and weight loss during pyrolysis [20]. The effect of main biomass constituents on the weight loss profile was identified and the effect of their interactions on weight loss rate was observed. However, in case of combustion process, the application of this kind of mathematical and statistical model to this research field is still scarce.

In the present study, the effect of main biomass constituents and their interactions was screened and the simplified models for the prediction of kinetic values for biomass oxidation were developed using The RSM based on SLD. The synthetic biomass oxidation was observed in TGA. The kinetic values were then calculated using iso-conversional methods and analytical method. Finally, the relationship between biomass components and kinetic values were expressed in terms of cubic models. The statistical results and proposed models obtained from several kinetic methods were compared. In addition, contour plots were provided in this study and described in detail. 


\section{Materials and Methods}

\subsection{Materials}

The synthesized biomass used in this work consisted of pure $\alpha$-cellulose, hemicellulose (xylan), Organosolv lignin and their mixtures. Cellulose, hemicellulose, and lignin were purchased from Sigma Aldrich.

\subsection{Experimental Design based on Simplex-lattice Design}

The influences of cellulose, hemicellulose and lignin on decomposition behavior of biomass under oxidative atmosphere were studied using RSM with SLD. The kinetic parameters including activation energy $\left(E_{a}\right)$, frequency factor $(A)$ and reaction order $(n)$ represented the decomposition behavior and used to simulate the decomposition profiles. With respect to SLD, the three-component system was designed as shown in Fig. 1. This figure also shows the ratios of each component. Thirteen combinations composed of three pure components, six points of two-component mixtures and four points of three-component mixtures. The summation between mass fraction of cellulose $\left(X_{1}\right)$, mass fraction of hemicellulose $\left(X_{2}\right)$ and mass fraction of lignin $\left(X_{3}\right)$ must be one. For each combination, the experiments were performed using four constant heating rates with two replicates.

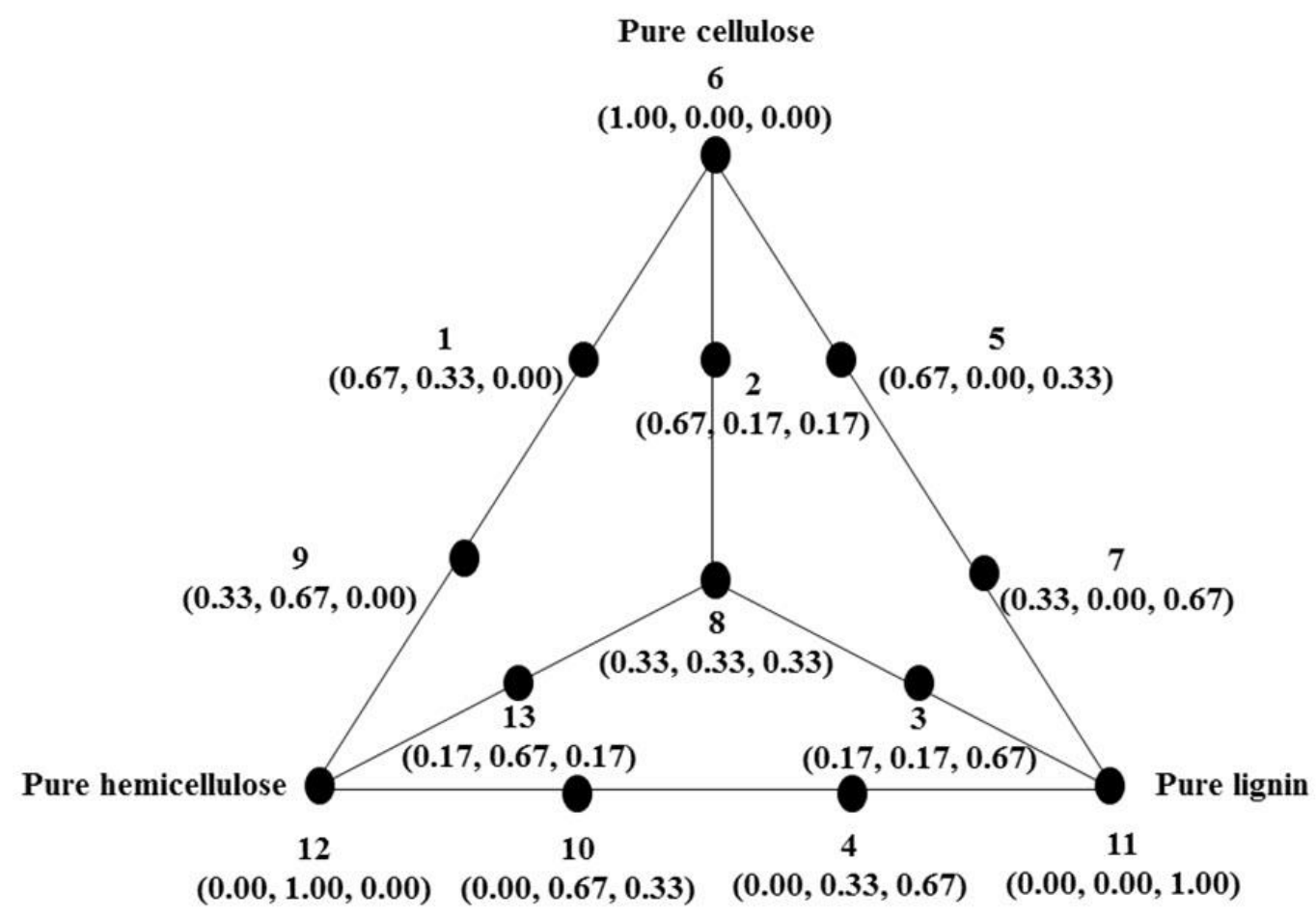

Fig. 1. 13 points augmented simplex lattice design. (Numbers in parenthesis represents mass fraction of cellulose, hemicellulose and lignin, respectively).

\subsection{Thermogravimetric Analysis (TGA)}

The weight loss and differential weight loss of synthesized biomass and real biomass oxidation as functions of temperature and time was observed using thermogravimetric/ differential thermal analyzer (Perkin Elmer TG/DTA Analyzer) under air atmosphere. The flow rate of air was $50 \mathrm{~mL} \mathrm{~min}{ }^{-1}$. Approximately 3.0 mg of sample was placed into an aluminium pan and then heated from 30 to $1000{ }^{\circ} \mathrm{C}$ at four linear heating rates $\left(5,10,20\right.$ and $\left.40{ }^{\circ} \mathrm{C} \mathrm{min}^{-1}\right)$.

\subsection{Derivation of Kinetic Parameters from TGA Data}


For the non-isothermal system, the sample mass was recorded as a function of temperature and time. The rate of decomposition $(d \alpha / d t)$ can be expressed as:

$$
\frac{d \alpha}{d t}=k(T) f(\alpha)
$$

where $a$ is the fraction of convertible part of biomass decomposed at any time $t$ which is defined by Eq. (2) and $k(T)$ is the rate constant given by Arrhenius equation. The function $f(\alpha)$ depends on the decomposition mechanism.

$$
\alpha=\frac{W_{0}-W}{W_{0}-W_{a s h}}
$$
(3).

By applying Arrhenius equation and the constant heating rate $(\beta=d T / d t)$, Eq. (1) can be written as Eq.

$$
\frac{d \alpha}{f(\alpha)}=\frac{A}{\beta} \exp \left(-\frac{E_{a}}{R T}\right) d T
$$

where $A$ is the frequency factor $\left(\mathrm{s}^{-1}\right), E_{a}$ is the activation energy $(\mathrm{kJ} / \mathrm{kmol}), \mathrm{R}$ is a gas constant $(8.314$ $\mathrm{kJ} / \mathrm{kmol} . \mathrm{K})$ and $T$ is the reaction temperature (K).

To simplify the equation, single step decomposition reaction was assumed. Therefore, function $f(\alpha)$ is defined as $(1-\alpha)^{n}$. Then, the integrated form of Eq. (3) for $1^{\text {st }}$ order and $n^{\text {th }}$ order of reaction can be written as Eqs. (4) and (5), respectively.

For $1^{\text {st }}$ order of reaction

$$
\alpha=1-\exp \left\{-\frac{A R T^{2}}{\beta E_{a}}\left(1-\frac{2 R T}{E_{a}}\right) \exp \left(-\frac{E_{a}}{R T}\right)\right\}
$$

For $n^{\text {th }}$ order of reaction

$$
\alpha=1-\left\{1-(n-1)\left(-\frac{A R T^{2}}{\beta E_{a}}\right)\left(1-\frac{2 R T}{E_{a}}\right) \exp \left(-\frac{E_{a}}{R T}\right)\right\}^{\frac{1}{1-n}}
$$

Hereafter, Eqs. (4) and (5) were called as analytical models. To calculate the kinetic parameters, the TGA curves were fitted with the analytical models by means of maximizing the regression coefficient $\left(\mathrm{R}^{2}\right)$. Then, a set of kinetic values those shows the better fit to the TGA data will be chosen for developing the correlation between biomass compositions and kinetic parameters.

In this study, other well-known kinetic models including Kissinger-Akahira-Sunose Model (KAS) and Ozawa-Flynn-Wall (OFW) were also applied for the calculation. These iso-conversional methods also consider the single step decomposition reaction as analytical models [21]. Eq. (3) was rearranged and function $g(\alpha)$ was given as Eq. (6).

$$
g(\alpha)=\int_{0}^{\alpha} \frac{d \alpha}{f(\alpha)}=\int_{0}^{\alpha} \frac{A}{\beta} \exp \left(-\frac{E_{a}}{R T}\right) d T=\frac{A E_{a}}{\beta R} p\left(\frac{E_{a}}{R T}\right)
$$

where the term $p\left(E_{a} / R T\right)$ is the temperature integral. The difference of KAS and OFW methods is due to the approximation for solving the equation. In case of KAS, the approximation is proposed to be [22-24]:

$$
p\left(\frac{E_{a}}{R T}\right)=\exp \left(-\frac{E_{a}}{R T}\right) \times\left(\frac{E_{a}}{R T}\right)^{-2}
$$

Substitutes Eq. (7) into Eq.(6) and takes logarithm. Then, Eq. (6) becomes:

$$
\ln \left(\frac{\beta}{T^{2}}\right)=\ln \left(\frac{A E_{a}}{R g(\alpha)}\right)-\frac{E_{a}}{R T}
$$

The $E_{a}$ and $A$ can be calculated by plotting curve of $\ln \left(\beta / T^{2}\right)$ against $1 / T$.

In case of OFW, The approximation of this model is based on Doyle's approximation [22, 25-27]. Therefore, Eq. (6) becomes:

$$
\log \beta=\log \left(A \frac{E_{a}}{\operatorname{Rg}(\alpha)}\right)-2.315-0.457\left(\frac{E_{a}}{R T}\right)
$$


The $E_{a}$ and $A$ can be calculated by plotting curve of $\log (\beta)$ against $1 / T$. In case of any order $n$ of KAS and OFW methods, $n$ was calculated by Kissinger index of shape equation using differential thermal analysis (DTA) curves $[23,28]$. The $g(\alpha)$ is equal to $-\ln (1-\alpha)$ for first-order kinetics and $(n-1)^{-1}(1-\alpha)^{(1-n)}$ for any order $n$.

\subsection{Statistical Analysis and Mathematical Model}

A statistical test called ANOVA (analysis of variance) and response surface methodology (RSM) were used to evaluate the effect of each biomass constituent, determine the most significant factor on the desired response ( $E_{a}, A$ or $n$ obtained from various methods) and also generate the statistical models for predicting the kinetic parameters. The values of each response were transformed by taking natural logarithm previous to the statistical analysis in order to satisfy assumptions of linearity and homogeneity of variance. The ANOVA tables of response surface model for each response were provided to summarize the test performed. The Model $p$-value below 0.05 implies the model is significant.

Since the response was the function of mass fraction of cellulose, hemicellulose and lignin, the behavior of the response could be explained by the following cubic equation (Eq. (10)) $[17,19]$.

$$
\begin{aligned}
\ln Y & =a_{1} X_{1}+a_{2} X_{2}+a_{3} X_{3}+a_{12} X_{1} X_{2}+a_{13} X_{1} X_{3}+a_{23} X_{2} X_{3}+a_{123} X_{1} X_{2} X_{3} \\
& +a_{1-2} X_{1} X_{2}\left(X_{1}-X_{2}\right)+a_{1-3} X_{1} X_{3}\left(X_{1}-X_{3}\right)+a_{2-3} X_{2} X_{3}\left(X_{2}-X_{3}\right)
\end{aligned}
$$

where $\ln Y$ is natural logarithm of estimated response. The $a_{1}, a_{2}, a_{3}, a_{12}, a_{13}, a_{23}, a_{123}, a_{1-2}, a_{1-3}$ and $a_{2-3}$ are constant coefficients for linear and non-linear (interaction) terms. The models were also used to generate the ternary contour plots in order to observe the influence of biomass compositions on $E_{a}, A$ and $n$. The models and ternary contour plots for estimated kinetic values obtained from different kinetic models were produced to observe the individual effects of the selected factors and interactions between them. Moreover, these generated models and ternary plots were compared to each other as well.

\section{Results and Discussion}

\subsection{Combustion of Main Chemical Compositions of Biomass and Their Mixtures}

Combustion of the main chemical compositions of biomass including cellulose, hemicelluloses, lignin and their blends were studied using a TGA analyzer. Fig. 2 shows the weight loss profiles and rate of weight loss curves as a function of temperature at a heating rate of $5{ }^{\circ} \mathrm{C} / \mathrm{min}$.

It could be found that significant variations between different compositions existed due to differences in their chemical compositions. From Fig. 2(a), two decomposition zones were observed for both cellulose and hemicellulose combustion. The first decomposition zone was taken account to the pyrolytic reactions of biomass components. The degradation reaction is accompanied by the release of water, gaseous products and eventual formation of char [8]. During combustion reaction, with a presence of oxygen, the char residues underwent ignition resulting in an appearance of the second decomposition zone. Compared to hemicellulose combustion, the weight loss of cellulose started at higher temperature and finished at lower temperature. This behavior is attributed to the fact that the cellulose composes of only one simple repeating unit, cellubiose. Therefore, cellulose decomposes through a rapid depolymerization process by cleavage of glycosidic bonds during the combustion process [29]. In contrast, xylan, which was used as hemicellulose model in this work, was the least thermally stable component of biomass. The onset temperature of xylan combustion was lower than that of cellulose. Fig. 2(d) also illustrated that the maximum of weight loss in case of xylan combustion occurred at lower temperature than that of cellulose combustion. For the blending of cellulose and hemicellulose, as shown in Fig. 2(a) and 2(d), TG and DTG curves of the blends laid between those of the individual biomass components. At higher blending ratio of hemicellulose (xylan), more volatiles of polypentose was released which shifted the volatile release onset temperature to lower value. 

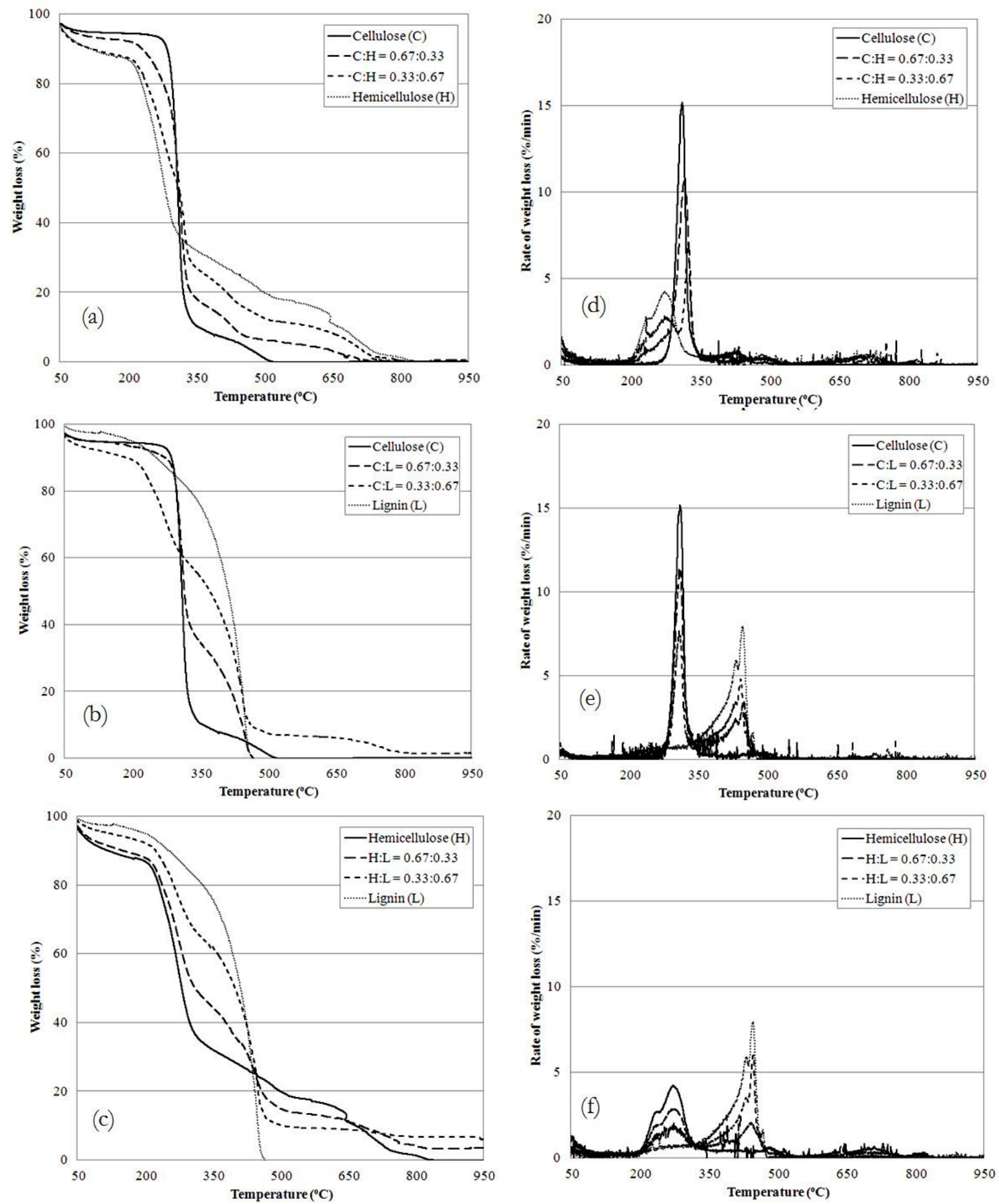

Fig. 2. TGA data for the combustion of cellulose/hemicellulose (a), cellulose/lignin (b) and hemicellulose/lignin (c) and DTG data for the combustion of cellulose/hemicellulose (d), cellulose/lignin (e) and hemicellulose/lignin (f).

Fig. 2(b) and 2(c) shows the comparison of TGA data between lignin combustion and other components. It could be seen that lignin shows a gradual decomposition over a broad temperature range. It started to decomposition at lower temperature compared to cellulose whilst its final decomposition temperature was higher than that of hemicellulose since it makes of aromatic compounds that have numerous branches and heavily cross linked. The complicated interconnected structure provided high thermal stability to lignin. The maximum weight loss rate of lignin thus appeared at the highest temperature. From Fig. 2(e) and 2(f), the numbers of DTG peaks corresponded to the main decompositions. In case of 
blending, the magnitude of peaks related to the blending ratios and laid between those of the individual biomass components.

\subsection{Evaluation of Kinetic Values}

The kinetic values of synthetic biomass combustion calculated from KAS, OFW and Analytical methods are presented in Table 1(a), 1(b) and 1(c), respectively. The combustion of each synthetic biomass blending ratio were conducted at 4 heating rates with 2 replicates. The results demonstrated that kinetic values calculated from KAS (Table 1(a)) were comparable to those calculated from OFW (Table 1(b)) since they were developed from the same procedure, excepting an approximation of temperature integral term. For KAS and OFW methods, it should be noted that the values of $E_{a}$ calculated from first-order and any-order kinetics had the same values. The $E_{a}$ was calculated from the slope of linear plots without any influence of other parameters whilst the $A$ and $n$ were calculated from the intercept of linear plots. In addition, the values of $\mathrm{n}$ calculated from both KAS and OFW methods were equal because they were calculated from the same DTA curve.

From Table 1(a) and 1(b), the $E_{a}$ and $A$ were about $88-141 \mathrm{~kJ} / \mathrm{mol}$ and $1 \mathrm{E}+5-8 \mathrm{E}+12 \mathrm{~min}^{-1}$ whilst $n$ were approximately $1.2-1.7$. It could be observed that synthetic biomass with high lignin blending ratios (Sample code 3, 4 and 7) and pure lignin (Sample code 11) gave relatively low $E_{a}$ and $A$. It was because of the complexity of lignin structure as mention earlier. The decomposition of lignin composes of several chemical reactions, including the cleavage of $\alpha$ - and $\beta$-aryl-aryl-ether linkages, splitting of aliphatic side chains from the aromatic rings and cleavage of carbon-carbon linkage between lignin units [30], which occurs simultaneously. Coincidentally, oxygen in air promoted the formation of volatiles and gasified the residue. In cases of cellulose and xylan combustion, the decomposition of these components occurred faster than lignin since they have much simpler repeating unit. Therefore, the $E_{a}$ and $A$ provided from these cases were higher than a case of lignin combustion. However, the results exhibited that the values of $E_{a}$ and $A$ obtained from the blends cannot be calculated from the arithmetic method, indicating the interaction between each component.

Considering the Analytical method, the calculated $E_{a}$ and $A$ (for both cases of first-order kinetic and any-order kinetics) values were higher than those obtained from other cases. Moreover, the relationship between kinetic values calculated from this method and biomass composition was not obviously observed, especially a case of first-order kinetic.

Table 1. Predicted kinetic values obtained from different kinetic models. (a) KAS

\begin{tabular}{|c|c|c|c|c|c|}
\hline \multirow{2}{*}{$\begin{array}{c}\text { Sample } \\
\text { code }\end{array}$} & \multicolumn{2}{|c|}{$n=1$} & \multicolumn{3}{|c|}{$n \neq 1$} \\
\hline & $E_{a}(\mathrm{~kJ} / \mathrm{mol})$ & $A\left(\min ^{-1}\right)$ & $E_{a}(\mathrm{~kJ} / \mathrm{mol})$ & $A\left(\min ^{-1}\right)$ & $n$ \\
\hline 1 & 101.2 & $1.4 \mathrm{E}+08$ & 101.2 & $2.3 \mathrm{E}+08$ & 1.6 \\
\hline 2 & 138.6 & $2.8 \mathrm{E}+11$ & 138.6 & $4.2 \mathrm{E}+11$ & 1.4 \\
\hline 3 & 86.2 & $1.5 \mathrm{E}+05$ & 86.2 & $2.3 \mathrm{E}+05$ & 1.5 \\
\hline 4 & 88.4 & $2.4 \mathrm{E}+05$ & 88.4 & 4.4E+05 & 1.7 \\
\hline 5 & 119.1 & $5.0 \mathrm{E}+09$ & 119.1 & $9.3 \mathrm{E}+09$ & 1.6 \\
\hline 6 & 103.8 & $3.6 \mathrm{E}+08$ & 103.8 & $6.4 \mathrm{E}+08$ & 1.6 \\
\hline 7 & 88.2 & $2.6 \mathrm{E}+05$ & 88.2 & $3.0 \mathrm{E}+05$ & 1.2 \\
\hline 8 & 113.9 & $1.7 \mathrm{E}+09$ & 113.9 & $2.4 \mathrm{E}+09$ & 1.4 \\
\hline 9 & 119.1 & $5.0 \mathrm{E}+09$ & 119.1 & $9.3 \mathrm{E}+09$ & 1.6 \\
\hline 10 & 137.2 & $2.9 \mathrm{E}+12$ & 137.2 & $4.6 \mathrm{E}+12$ & 1.5 \\
\hline 11 & 98.2 & $1.3 \mathrm{E}+06$ & 98.2 & $2.0 \mathrm{E}+06$ & 1.5 \\
\hline 12 & 121.4 & $9.5 \mathrm{E}+10$ & 121.4 & $1.5 \mathrm{E}+11$ & 1.5 \\
\hline 13 & 120.5 & $6.9 \mathrm{E}+09$ & 120.5 & $1.4 \mathrm{E}+10$ & 1.7 \\
\hline
\end{tabular}


(b) OFW

\begin{tabular}{|c|c|c|c|c|c|}
\hline \multirow{2}{*}{$\begin{array}{c}\text { Sample } \\
\text { code }\end{array}$} & \multicolumn{2}{|c|}{$n=1$} & \multicolumn{3}{|c|}{$n \neq 1$} \\
\hline & $E_{a}(\mathrm{~kJ} / \mathrm{mol})$ & $A\left(\min ^{-1}\right)$ & $E_{a}(\mathrm{~kJ} / \mathrm{mol})$ & $A\left(\min ^{-1}\right)$ & $n$ \\
\hline 1 & 106.0 & $5.1 \mathrm{E}+08$ & 106.0 & $8.7 \mathrm{E}+08$ & 1.6 \\
\hline 2 & 141.5 & $5.7 \mathrm{E}+11$ & 141.5 & $8.4 \mathrm{E}+11$ & 1.4 \\
\hline 3 & 94.1 & $1.2 \mathrm{E}+06$ & 94.1 & $1.8 \mathrm{E}+06$ & 1.5 \\
\hline 4 & 96.1 & $1.7 \mathrm{E}+06$ & 96.1 & $3.2 \mathrm{E}+06$ & 1.7 \\
\hline 5 & 132.0 & $1.6 \mathrm{E}+11$ & 132.0 & $2.5 \mathrm{E}+11$ & 1.5 \\
\hline 6 & 108.4 & $1.3 \mathrm{E}+09$ & 108.4 & $2.2 \mathrm{E}+09$ & 1.6 \\
\hline 7 & 95.9 & $1.9 \mathrm{E}+06$ & 95.9 & $2.2 \mathrm{E}+06$ & 1.2 \\
\hline 8 & 118.2 & $5.1 \mathrm{E}+09$ & 118.2 & $7.3 \mathrm{E}+09$ & 1.4 \\
\hline 9 & 123.1 & $1.4 \mathrm{E}+10$ & 123.1 & $2.6 \mathrm{E}+10$ & 1.6 \\
\hline 10 & 139.5 & $5.2 \mathrm{E}+12$ & 139.5 & $8.1 \mathrm{E}+12$ & 1.5 \\
\hline 11 & 105.5 & 7.6E+06 & 105.5 & $1.2 \mathrm{E}+07$ & 1.5 \\
\hline 12 & 124.4 & $2.1 \mathrm{E}+11$ & 124.4 & $3.4 \mathrm{E}+11$ & 1.5 \\
\hline 13 & 124.4 & $1.9 \mathrm{E}+10$ & 124.4 & $3.7 \mathrm{E}+10$ & 1.7 \\
\hline
\end{tabular}

(c) Analytical models

\begin{tabular}{ccccccc}
\hline \multirow{2}{*}{$\begin{array}{c}\text { Sample } \\
\text { code }\end{array}$} & \multicolumn{2}{c}{$\mathbf{n = 1}$} & & \multicolumn{3}{c}{$\mathbf{n \neq 1}$} \\
\cline { 2 - 3 } \cline { 5 - 6 } & $\boldsymbol{E}_{\boldsymbol{a}}(\mathbf{k J} / \mathbf{m o l})$ & $\boldsymbol{A}\left(\mathbf{m i n}^{-1}\right)$ & & $\boldsymbol{E}_{\boldsymbol{a}}(\mathbf{k J} / \mathbf{m o l})$ & $\boldsymbol{A}\left(\mathbf{m i n}^{-1}\right)$ & $\boldsymbol{n}$ \\
\hline 1 & 127.9 & $5.1 \mathrm{E}+08$ & & 114.8 & $8.7 \mathrm{E}+08$ & 1.4 \\
2 & 159.6 & $2.8 \mathrm{E}+11$ & & 145.0 & $3.6 \mathrm{E}+11$ & 1.4 \\
3 & 152.0 & $1.5 \mathrm{E}+09$ & & 117.5 & $2.3 \mathrm{E}+08$ & 1.3 \\
4 & 149.9 & $1.0 \mathrm{E}+09$ & & 100.0 & $2.8 \mathrm{E}+07$ & 1.3 \\
5 & 154.2 & $6.9 \mathrm{E}+10$ & & 127.7 & $2.0 \mathrm{E}+10$ & 1.3 \\
6 & 123.7 & $3.6 \mathrm{E}+08$ & & 116.7 & $6.4 \mathrm{E}+08$ & 1.6 \\
7 & 151.0 & $2.6 \mathrm{E}+08$ & & 100.0 & $2.4 \mathrm{E}+08$ & 1.2 \\
8 & 139.5 & $2.2 \mathrm{E}+09$ & & 113.2 & $2.4 \mathrm{E}+09$ & 1.2 \\
9 & 140.5 & $1.4 \mathrm{E}+10$ & & 113.7 & $2.6 \mathrm{E}+10$ & 1.2 \\
10 & 167.5 & $2.8 \mathrm{E}+12$ & & 134.6 & $5.0 \mathrm{E}+12$ & 1.1 \\
11 & 155.2 & $8.3 \mathrm{E}+08$ & & 107.6 & $4.0 \mathrm{E}+07$ & 1.4 \\
12 & 174.4 & $5.2 \mathrm{E}+12$ & & 114.8 & $2.4 \mathrm{E}+11$ & 1.2 \\
13 & 143.9 & $1.5 \mathrm{E}+10$ & & 114.4 & $1.8 \mathrm{E}+10$ & 1.1 \\
\hline
\end{tabular}

The difference between Analytical method and the others occurred because this method attempted to fit the model with experimental data without considering the combustion behavior. The apparent kinetic values provided by this method came from the average of 8 individual experiments (4 heating rates with 2 replicates) whilst iso-conversional method, KAS and OFW methods, approximated the reaction order from DTA data and calculate other kinetic values from larger information (simultaneously calculated the $E_{a}$ and $A$ from 4 heating rates and progress of conversion). However, Analytical method for any-order kinetic provided more comparable kinetic values to iso-conversional method. As can be seen in Fig. 3, the conversion curve obtained from a case of any-order kinetic showed the better fit to an experimental data and gave very high $\mathrm{R}^{2}(0.98)$ compared to that obtained from a case of first-order kinetic (0.94). Therefore, an apparent reaction order of biomass combustion was greater than one. 


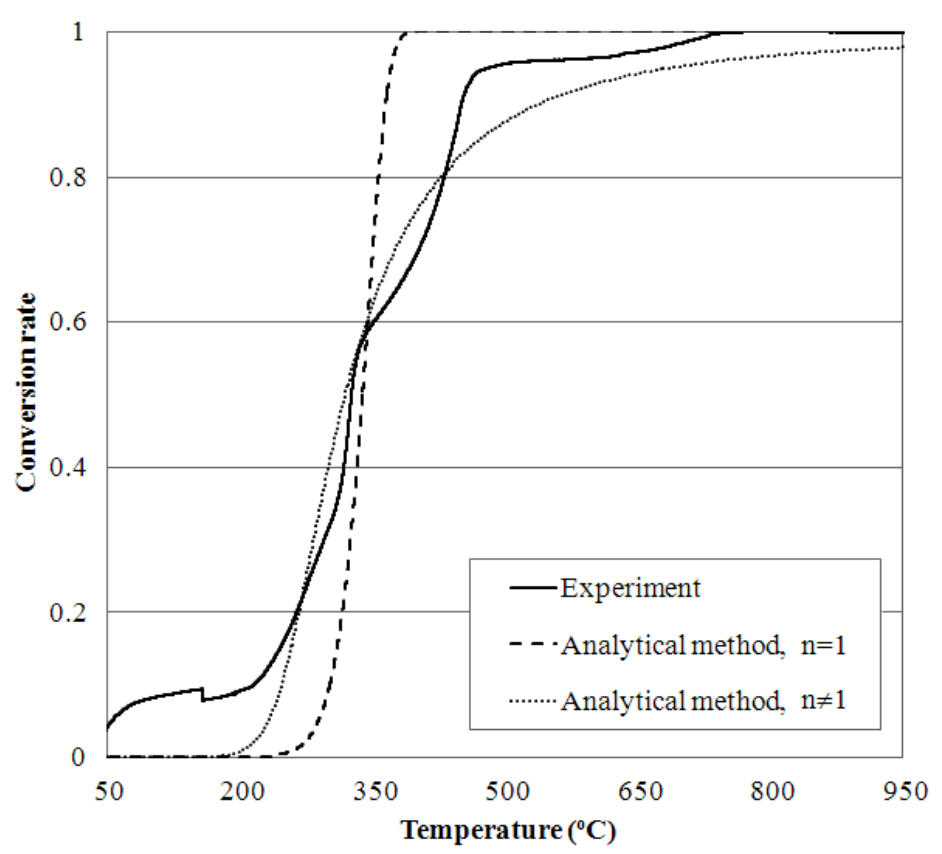

Fig. 3. Relationship between temperature and conversion (wt./wt.) of biomass pyrolysis obtained from Analytical methods for first-order kinetics and any-order kinetics.

\subsection{Statistical Analysis and Modeling}

\subsubsection{Analysis of variance}

After transforming the data by applying natural logarithm, the effects for all model terms were calculated. The statistical values such as F-value and $p$-value were used for indicating the factors those had significant effect on the response. ANOVA results for kinetic values obtained from KAS, OFW and Analytical methods have been summarized in Table 2(a), 2(b) and 2(c), respectively. The very low probability values $(<0.05)$ indicated that all the linear terms of individual biomass components $\left(X_{1}, X_{2}\right.$ and $\left.X_{3}\right)$ were statistically significant for frequency factor estimated by using KAS and OFW methods. In addition, in case of OFW method, an interaction term between mass fraction of cellulose and lignin, $X_{1} X_{3}\left(X_{1}-X_{3}\right)$, had significant effect on frequency factor and activation energy as well. However, the statistical results showed that none of cubic terms was the prominent factor that had significant effect on reaction order obtained by using KAS and OFW methods.

In case of Analytical method, the linear terms were found to have remarkable effects on activation energy (first-order kinetic) and reaction order. Moreover, some interaction terms such as $X_{1} X_{3}, X_{1} X_{2}\left(X_{1}\right.$ $\left.X_{2}\right)$ and $X_{2} X_{3}\left(X_{2}-X_{3}\right)$ also had significant effect on reaction order whilst the other factors were not significantly influential $(\mathrm{P}>0.05)$. To show the interactions between mass and the kinetic values, the regression models were generated and contour plots were profiled as discussed further down. 

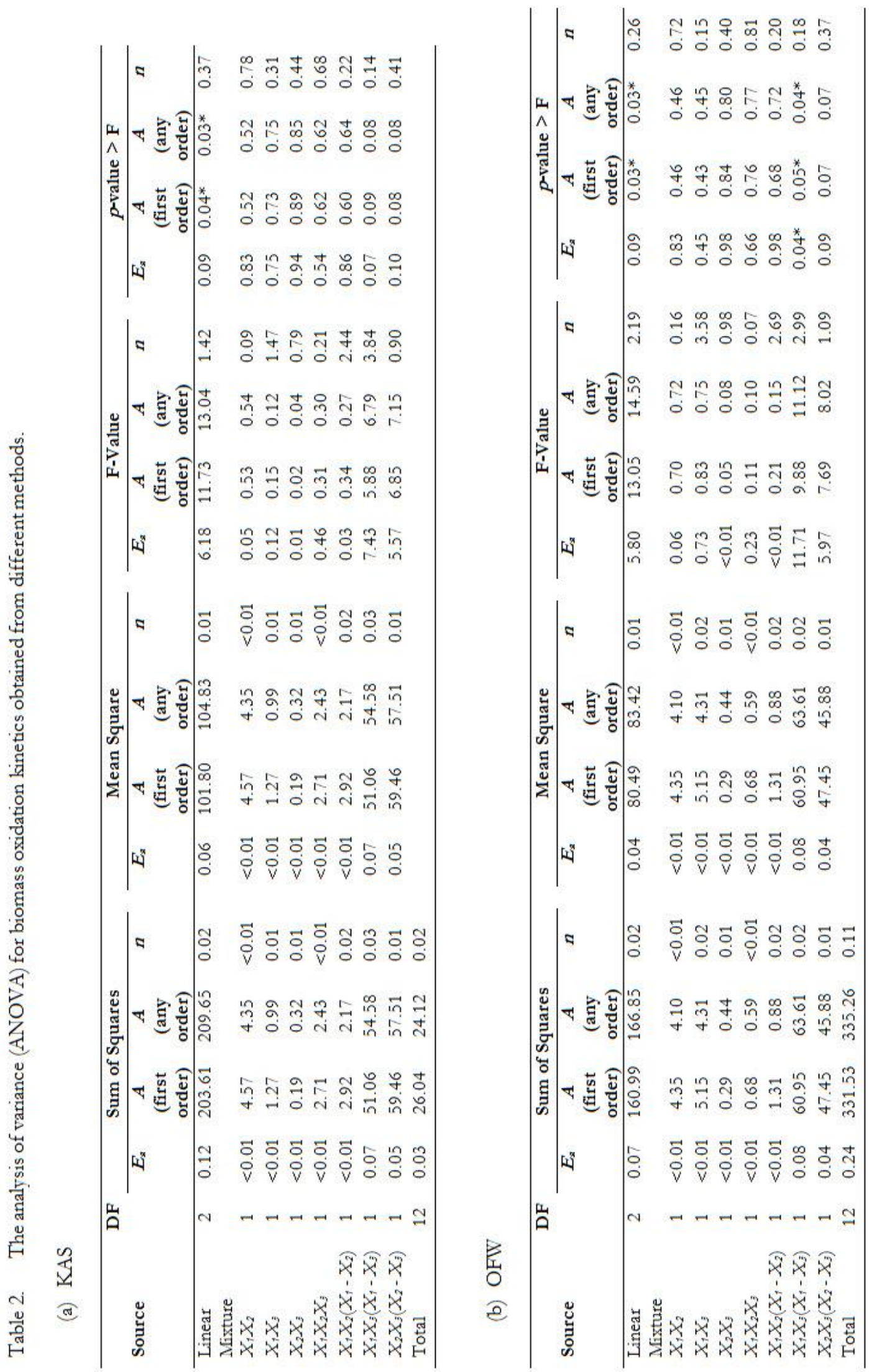


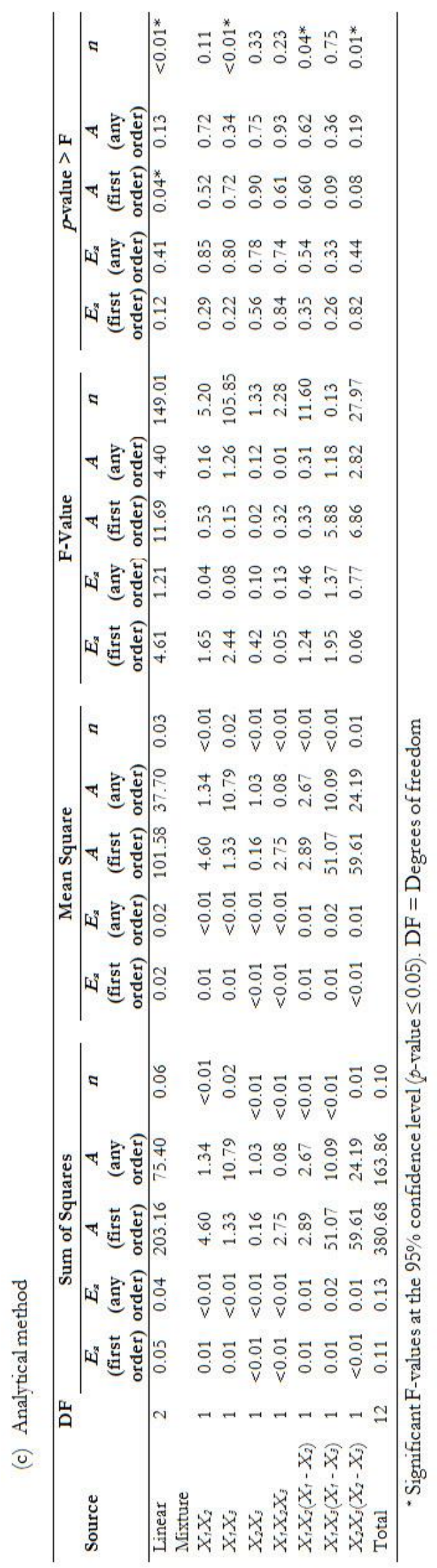




\subsubsection{Modeling and ternary contour plot}

Generally, the model terms in the cubic equation were calculated after elimination of some insignificant variables and their interactions which have the low $p$-value $(<0.05)$. However, in this study, all terms were included in the models to maximize the accuracy, in terms of $\mathrm{R}^{2}$ ), of models. The generated regression models for kinetic values obtained from KAS, OFW and Analytical methods have been summarized in Table 3. For KAS and OFW methods, the regression models with high $\mathrm{R}^{2}$ values (varied from $0.91-0.95$ ) for predicting $E_{a}$ and $A$ (6 models) are obtained. These high $\mathrm{R}^{2}$ coefficients ensured a fitting of the cubic models to the experimental data. Therefore, these models could be used to predict the $E_{a}$ and $A$ values from mass fractions of biomass compositions. However, in case of $n$, the $\mathrm{R}^{2}$ values were relatively low $(0.80$ for KAS method and 0.84 for OFW method) but they were probably acceptable. Therefore, these proposed models were accurately employed for predicting kinetic parameters of synthetic biomass combustion. In case of Analytical method, $\mathrm{R}^{2}$ coefficients indicated that the proposed regression models provided quite lower accurate kinetic values, excepted $n$. As mentioned earlier, this method was used to calculate the apparent kinetic values by forced fitting the model to TGA curve. The calculated kinetic values were quite poorly used to describe the biomass combustion behavior and also the relationship between biomass components.

Table 3. The regression models for biomass pyrolysis kinetics obtained from different methods.

\begin{tabular}{|c|c|c|c|c|}
\hline \multicolumn{2}{|l|}{ Response } & Regression models in terms of actual factors & $\mathbf{R}^{2}$ & SD \\
\hline \multirow[t]{4}{*}{ KAS } & $E_{a}$ & $\begin{aligned} \operatorname{Ln} E_{a}= & 4.64 X_{1}+4.81 X_{2}+4.59 X_{3}-0.10 X_{1} X_{2}+0.15 X_{1} X_{3}-0.04 X_{2} X_{3}+1.97 X_{1} X_{2} X_{3} \\
& +0.16 X_{1} X_{2}\left(X_{1}-X_{2}\right)+2.30 X_{1} X_{3}\left(X_{1}-X_{3}\right)+2.00 X_{2} X_{3}\left(X_{2}-X_{3}\right)\end{aligned}$ & 0.91 & 0.10 \\
\hline & $\begin{array}{l}A \text { (first } \\
\text { order) }\end{array}$ & $\begin{aligned} \operatorname{Ln} A= & 19.55 X_{1}+25.46 X_{2}+14.02 X_{3}-9.54 X_{1} X_{2}+5.04 X_{1} X_{3}+1.94 X_{2} X_{3} \\
& +47.95 X_{1} X_{2} X_{3}+14.60 X_{1} X_{2}\left(X_{1}-X_{2}\right)+60.87 X_{1} X_{3}\left(X_{1}-X_{3}\right) \\
& +65.70 X_{2} X_{3}\left(X_{2}-X_{3}\right)\end{aligned}$ & 0.93 & 2.95 \\
\hline & $\begin{array}{l}A \text { (any } \\
\text { order) }\end{array}$ & $\begin{aligned} \operatorname{Ln} A= & 20.14 X_{1}+25.91 X_{2}+14.43 X_{3}-9.31 X_{1} X_{2}+4.45 X_{1} X_{3}+2.53 X_{2} X_{3} \\
& +45.41 X_{1} X_{2} X_{3}+12.58 X_{1} X_{2}\left(X_{1}-X_{2}\right)+62.93 X_{1} X_{3}\left(X_{1}-X_{3}\right) \\
& +64.61 X_{2} X_{3}\left(X_{2}-X_{3}\right)\end{aligned}$ & 0.94 & 2.84 \\
\hline & $n$ & $\begin{aligned} \operatorname{Ln} n= & 0.48 X_{1}+0.41 X_{2}+0.37 X_{3}+0.12 X_{1} X_{2}-0.47 X_{1} X_{3}+0.35 X_{2} X_{3}-1.17 X_{1} X_{2} X_{3} \\
& -1.17 X_{1} X_{2}\left(X_{1}-X_{2}\right)+1.46 X_{1} X_{3}\left(X_{1}-X_{3}\right)-0.71 X_{2} X_{3}\left(X_{2}-X_{3}\right)\end{aligned}$ & 0.80 & 0.09 \\
\hline \multirow[t]{4}{*}{ OFW } & $E_{a}$ & $\begin{aligned} \operatorname{Ln} E_{a}= & 4.68 X_{1}+4.83 X_{2}+4.66 X_{3}-0.09 X_{1} X_{2}+0.31 X_{1} X_{3}-0.01 X_{2} X_{3}+1.12 X_{1} X_{2} X_{3} \\
& +0.01 X_{1} X_{2}\left(X_{1}-X_{2}\right)+2.34 X_{1} X_{3}\left(X_{1}-X_{3}\right)+1.67 X_{2} X_{3}\left(X_{2}-X_{3}\right)\end{aligned}$ & 0.92 & 0.08 \\
\hline & $\begin{array}{l}A \text { (first } \\
\text { order) }\end{array}$ & $\begin{aligned} \operatorname{Ln} A= & 20.85 X_{1}+26.23 X_{2}+15.77 X_{3}-9.30 X_{1} X_{2}+10.12 X_{1} X_{3}+2.38 X_{2} X_{3} \\
& +23.93 X_{1} X_{2} X_{3}+9.79 X_{1} X_{2}\left(X_{1}-X_{2}\right)+66.71 X_{1} X_{3}\left(X_{1}-X_{3}\right) \\
& +58.86 X_{2} X_{3}\left(X_{2}-X_{3}\right)\end{aligned}$ & 0.94 & 2.48 \\
\hline & $\begin{array}{l}A \text { (any } \\
\text { order) }\end{array}$ & $\begin{aligned} \operatorname{Ln} A= & 21.43 X_{1}+26.70 X_{2}+16.18 X_{3}-9.04 X_{1} X_{2}+9.26 X_{1} X_{3}+2.94 X_{2} X_{3} \\
& +22.38 X_{1} X_{2} X_{3}+8.01 X_{1} X_{2}\left(X_{1}-X_{2}\right)+68.15 X_{1} X_{3}\left(X_{1}-X_{3}\right) \\
& +57.88 X_{2} X_{3}\left(X_{2}-X_{3}\right)\end{aligned}$ & 0.95 & 2.39 \\
\hline & $n$ & $\begin{aligned} \operatorname{Ln} n= & 0.48 X_{1}+0.41 X_{2}+0.37 X_{3}+0.13 X_{1} X_{2}-0.64 X_{1} X_{3}+0.33 X_{2} X_{3}-0.59 X_{1} X_{2} X_{3} \\
& -1.05 X_{1} X_{2}\left(X_{1}-X_{2}\right)+1.11 X_{1} X_{3}\left(X_{1}-X_{3}\right)-0.67 X_{2} X_{3}\left(X_{2}-X_{3}\right)\end{aligned}$ & 0.84 & 0.08 \\
\hline \multirow[t]{5}{*}{$\begin{array}{l}\text { Analytical } \\
\text { method }\end{array}$} & $\begin{array}{l}E_{a} \text { (first } \\
\text { order) }\end{array}$ & $\begin{aligned} \operatorname{Ln} E_{a}= & 4.82 X_{1}+5.17 X_{2}+5.05 X_{3}-0.41 X_{1} X_{2}+0.50 X_{1} X_{3}-0.21 X_{2} X_{3}-0.46 X_{1} X_{2} X_{3} \\
& +0.68 X_{1} X_{2}\left(X_{1}-X_{2}\right)+0.85 X_{1} X_{3}\left(X_{1}-X_{3}\right)+0.15 X_{2} X_{3}\left(X_{2}-X_{3}\right)\end{aligned}$ & 0.86 & 0.07 \\
\hline & $\begin{array}{l}E_{a}(\text { any } \\
\text { order })\end{array}$ & $\begin{aligned} \operatorname{Ln} E_{a}= & 4.76 X_{1}+4.76 X_{2}+4.68 X_{3}-0.12 X_{1} X_{2}+0.15 X_{1} X_{3}+0.17 X_{2} X_{3}+1.32 X_{1} X_{2} X_{3} \\
& +0.73 X_{1} X_{2}\left(X_{1}-X_{2}\right)+1.26 X_{1} X_{3}\left(X_{1}-X_{3}\right)+0.94 X_{2} X_{3}\left(X_{2}-X_{3}\right)\end{aligned}$ & 0.64 & 0.13 \\
\hline & $\begin{array}{l}A \text { (first } \\
\text { order) }\end{array}$ & $\begin{aligned} \operatorname{Ln} A= & 19.56 X_{1}+25.46 X_{2}+14.02 X_{3}-9.57 X_{1} X_{2}+5.15 X_{1} X_{3}+1.77 X_{2} X_{3} \\
& +48.20 X_{1} X_{2} X_{3}+14.53 X_{1} X_{2}\left(X_{1}-X_{2}\right)+61.06 X_{1} X_{3}\left(X_{1}-X_{3}\right) \\
& +65.98 X_{2} X_{3}\left(X_{2}-X_{3}\right)\end{aligned}$ & 0.93 & 2.95 \\
\hline & $\begin{array}{l}A \text { (any } \\
\text { order) }\end{array}$ & $\begin{aligned} \operatorname{Ln} A= & 20.26 X_{1}+26.47 X_{2}+17.53 X_{3}-5.17 X_{1} X_{2}+14.66 X_{1} X_{3}+4.52 X_{2} X_{3} \\
& -8.23 X_{1} X_{2} X_{3}+13.96 X_{1} X_{2}\left(X_{1}-X_{2}\right)+27.14 X_{1} X_{3}\left(X_{1}-X_{3}\right) \\
& +42.03 X_{2} X_{3}\left(X_{2}-X_{3}\right)\end{aligned}$ & 0.84 & 2.93 \\
\hline & $n$ & $\begin{aligned} \operatorname{Ln} n= & 0.44 X_{1}+0.14 X_{2}+0.30 X_{3}-0.15 X_{1} X_{2}-0.68 X_{1} X_{3}-0.08 X_{2} X_{3}+0.65 X_{1} X_{2} X_{3} \\
& +0.43 X_{1} X_{2}\left(X_{1}-X_{2}\right)+0.04 X_{1} X_{3}\left(X_{1}-X_{3}\right)-0.66 X_{2} X_{3}\left(X_{2}-X_{3}\right)\end{aligned}$ & 0.99 & 0.01 \\
\hline
\end{tabular}

The contour plots in Fig. 4-6 show the effects of mass fraction of cellulose, hemicellulose and lignin on activation energy, frequency factor and reaction order obtained from different methods. Fig. 4(a), 4(b) and 4(d) illustrate that the synthetic biomass with high cellulose-hemicellulose content and low lignin content requires high $E_{a}$ for combustion process. Fig. 5 confirmed again the influence of biomass composition on the variation of $A$. The higher cellulose-hemicellulose blend provided higher value of $A$. Fig. 6 shows the influence of biomass composition on variation of $n$. It could be difficult to observe the 
trend. However, Fig. 6(c) which was obtained from Analytical method suggested that higher cellulose content provided higher reaction order whilst higher hemicellulose content provided lower value.
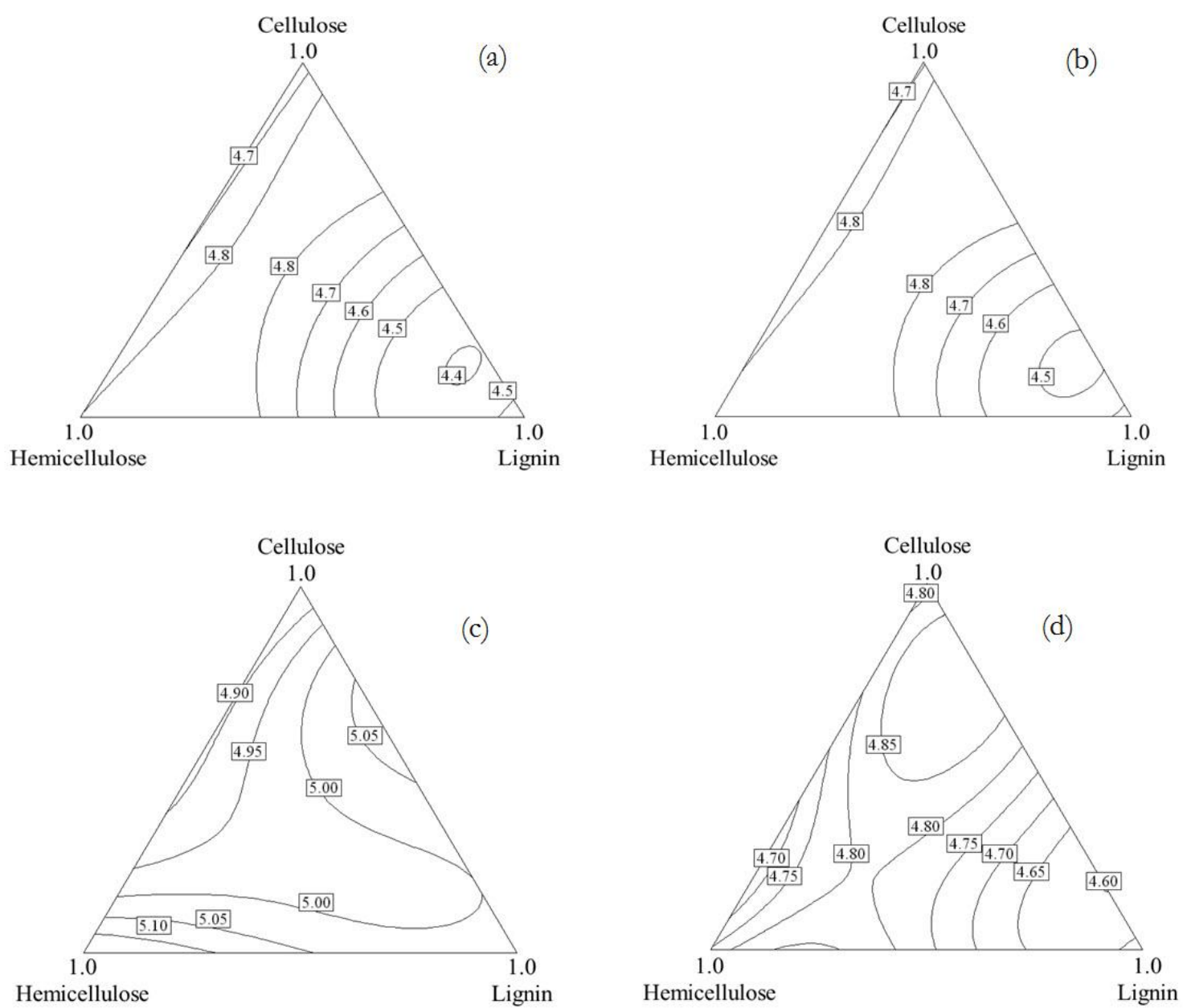

Fig. 4. Contour plots of predicted $\ln E_{a}$ for synthetic biomass combustion obtained from KAS method (a), OFW method (b), Analytical method for first-order kinetics (c) and Analytical method for any-order kinetics (d). 

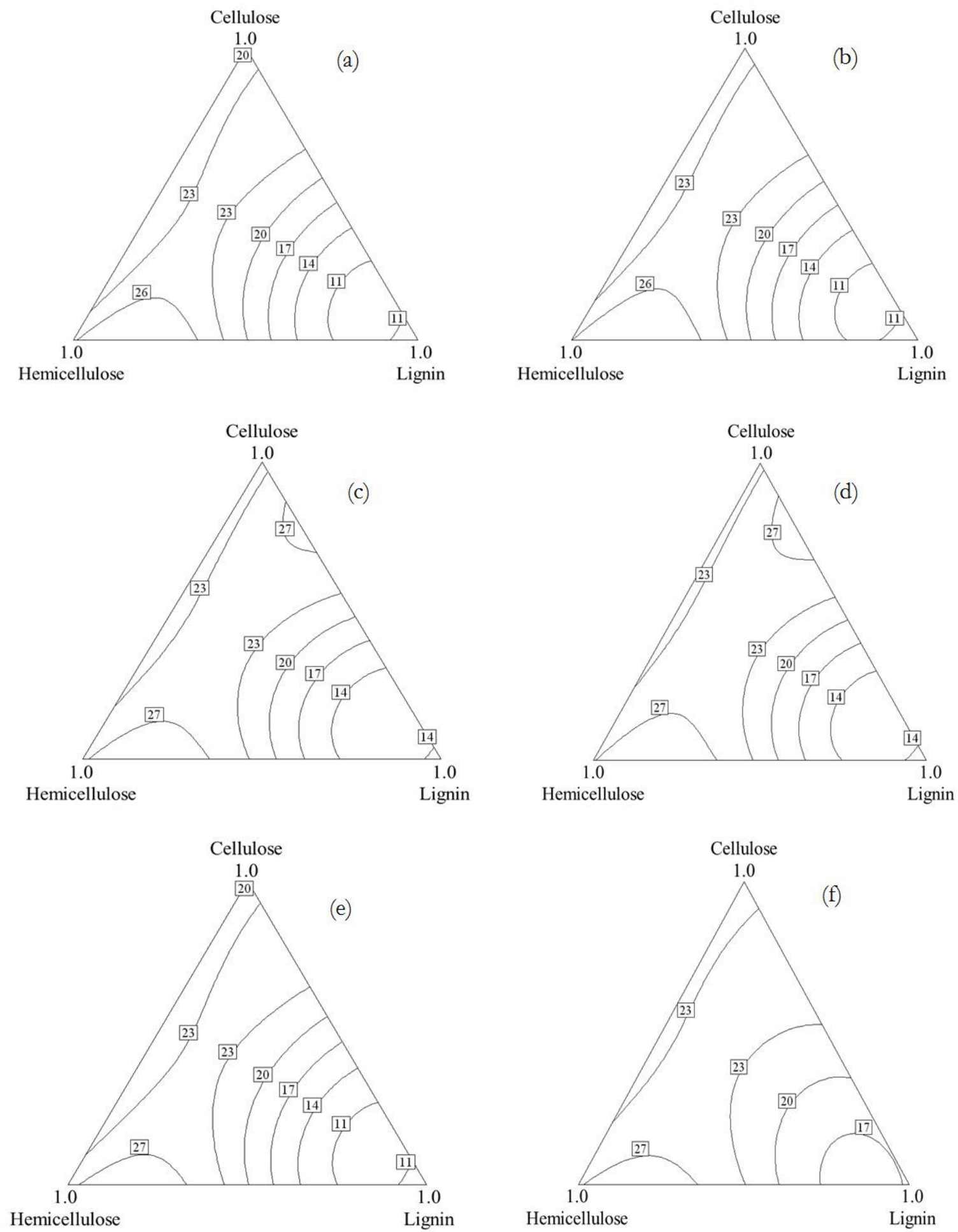

Fig. 5. Contour plots of predicted $\ln A$ for synthetic biomass combustion obtained from KAS method for first-order kinetics (a), KAS method for any-order kinetics (b), OFW method for first-order kinetics (c), OFW method for any-order kinetics (d), Analytical method for first-order kinetics (e) and Analytical method for any-order kinetics (f). 

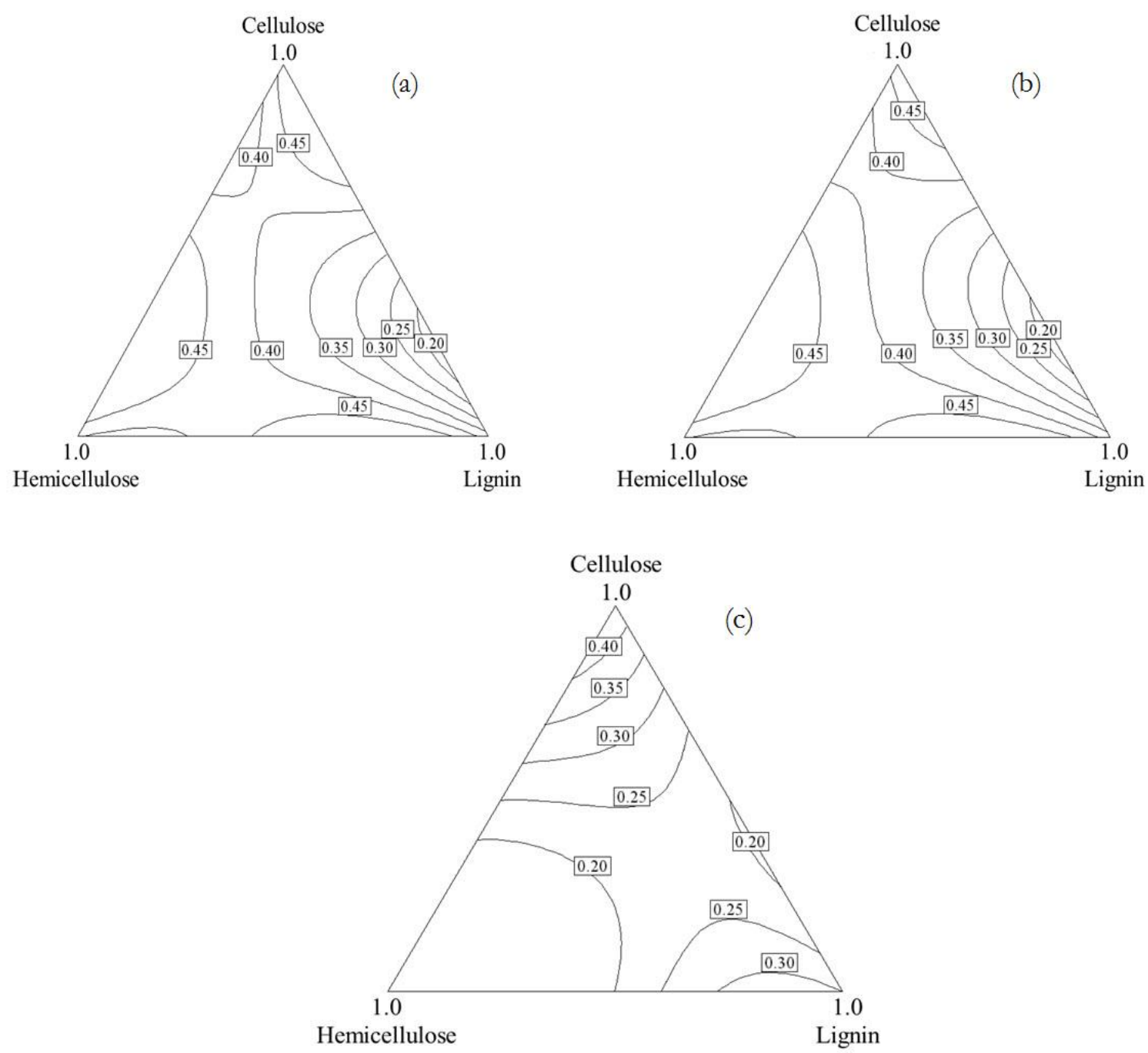

Fig. 6. Contour plots of predicted $\ln n$ for synthetic biomass combustion obtained from KAS method (a), OFW method (b) and Analytical method (c).

\section{Conclusions}

The effect of biomass composition on kinetic values for biomass combustion process was investigated. Based upon the experiments which were designed by using Simplex-lattice design, the RSM was used to observe the effect of cellulose, hemicellulose and lignin content and indicate the factors those have significant effect on the kinetic values. The results showed that the kinetic values calculated from KAS and OFW methods provided more reliable values compared to those calculated from Analytical method. The higher cellulose and hemicellulose fraction led to higher activation energy and frequency factor. By applying RSM, the statistical analysis also confirmed that all main variables could be considered significant. The proposed regression models with very high $\mathrm{R}^{2}$ coefficients demonstrated that experimental data were in close agreement with the predicted values. The RSM with Simplex-lattice design provided good information about the prediction of apparent kinetic values for biomass combustion.

\section{Acknowledgement}

This study was financially supported by the Grants from the Thailand Research Fund for fiscal year 2014 2016 (TRG5780205), the Grant for Development of New Faculty Staff (Ratchadaphisek Somphot Endowment Fund) of Chulalongkorn University, the Grant from Faculty of Science of Chulalongkorn University and the Center of Excellence on Petrochemical and Materials Technology, Chulalongkorn 
University. In addition, the authors would like to express their thanks to the Graduate School, Chulalongkorn University for partial financial support.

\section{References}

[1] J. Koppejan and S. V. Loo, The Handbook of Biomass Combustion and Co-firing. London, UK: Earthscan, 2008.

[2] M. A. B. Zanoni, H. Massard, and M. Ferreira Martins, "Formulating and optimizing a combustion pathways for oil shale and its semi-coke," Combustion and Flame, vol.159, pp. 3224-3234, 2012.

[3] M. Amutio, G. Lopez, R. Aguado, M. Artetxe, J. Bilbao, and M. Olazar, "Kinetic study of lignocellulosic biomass oxidative pyrolysis," Fuel, vol.95, pp. 305-311, 2012.

[4] E. Ranzi, M. Corbetta, F. Manenti, and S. Pierucci, "Kinetic modeling of the thermal degradation and combustion of biomass," Chemical Engineering Science, vol.110, pp. 2-12, 2013.

[5] R. Mehrabian, A. Shiehnejadhesar, R. Scharler, and I. Obernberger, "Multi-physics modelling of packed bed biomass combustion," Fuel, vol.122, pp. 164-178, 2014.

[6] M. V. Gil, D. Casal, C. Pevida, J. J. Pis, and F. Rubiera, "Thermal behaviour and kinetics of coal/biomass blends during co-combustion," Bioresource Technology, vol.101, pp. 5601-5608, 2010.

[7] G. Várhegyi, E. Mészáros, M. J. Antal, J. Bourke, and E. Jakab, "Combustion kinetics of corncob charcoal and partially demineralized corncob charcoal in the kinetic regime," Industrial \& Engineering Chemistry Research, vol.45, pp. 4962-4970, 2006.

[8] K. Cheng, W. T. Winter, and A. J. Stipanovic, "A modulated-TGA approach to the kinetics of lignocellulosic biomass pyrolysis/combustion," Polymer Degradation and Stability, vol.97, pp. 1606-1615, 2012.

[9] X. Fang, L. Jia, and L. Yin, "A weighted average global process model based on two-stage kinetic scheme for biomass combustion," Biomass and Bioenergy, vol.48, pp. 43-50, 2013.

[10] D. Shen, J. Ye, R. Xiao, and H. Zhang, "TG-MS analysis for thermal decomposition of cellulose under different atmospheres," Carbohydrate Polymers, vol.98, pp. 514-521, 2013.

[11] C. Chen, X. Ma, and K. Liu, "Thermogravimetric analysis of microalgae combustion under different oxygen supply concentrations," Applied Energy, vol.88, pp. 3189-3196, 2011.

[12] S. S. Idris, N. A. Rahman, and K. Ismail, "Combustion characteristics of Malaysian oil palm biomass, sub-bituminous coal and their respective blends via thermogravimetric analysis (TGA)," Bioresource Technology, vol.123, pp. 581-591, 2012.

[13] D. López-González, M. Fernandez-Lopez, J. L. Valverde, and L. Sanchez-Silva, "Thermogravimetric-mass spectrometric analysis on combustion of lignocellulosic biomass," Bioresource Technology, vol.143, pp. 562-574, 2013.

[14] M. Othman, Y.-H. Park, T. Ngo, S.-S. Kim, J. Kim, and K. Lee, "Thermogravimetric characteristics and pyrolysis kinetics of Giheung Respia sewage sludge," Korean Journal of Chemical Engineering, vol. 27, pp. 163-167, 2010.

[15] J. A. Conesa and A. Domene, "Biomasses pyrolysis and combustion kinetics through n-th order parallel reactions," Thermochimica Acta, vol. 523, pp. 176-181, 2011.

[16] S. Azevedo, L. M. Cunha, P. V. Mahajan, and S. C. Fonseca, "Application of simplex lattice design for development of moisture absorber for oyster mushrooms," Procedia Food Science, vol. 1, pp. 184 189, 2011.

[17] P. V. Rao and S. S. Baral, "Experimental design of mixture for the anaerobic co-digestion of sewage sludge," Chemical Engineering Journal, vol.172, pp. 977-986, 2011.

[18] Q. Liu, Z. Zhong, S. Wang, and Z. Luo, "Interactions of biomass components during pyrolysis: A TG-FTIR study," Journal of Analytical and Applied Pyrolysis, vol.90, pp. 213-218, 2011.

[19] S. Karaman, M. T. Yilmaz, and A. Kayacier, "Simplex lattice mixture design approach on the rheological behavior of glucomannan based salep-honey drink mixtures: An optimization study based on the sensory properties," Food Hydrocolloids, vol.25, pp. 1319-1326, 2011.

[20] H. Yang, R. Yan, H. Chen, C. Zheng, D. H. Lee, and D. T. Liang, "In-depth investigation of biomass pyrolysis based on three major components: hemicellulose, cellulose and lignin," Energy \& Fuels, vol. 20, pp. 388-393, 2005.

[21] T. Damartzis, D. Vamvuka, S. Sfakiotakis, and A. Zabaniotou, "Thermal degradation studies and kinetic modeling of cardoon (Cynara cardunculus) pyrolysis using thermogravimetric analysis (TGA)," Bioresource Technology, vol. 102, pp. 6230-6238, 2011. 
[22] J. E. White, W. J. Catallo, and B. L. Legendre, "Biomass pyrolysis kinetics: A comparative critical review with relevant agricultural residue case studies," Journal of Analytical and Applied Pyrolysis, vol. 91, pp. 1-33, 2011.

[23] H. E. Kissinger, "Reaction Kinetics in Differential Thermal Analysis," Analytical Chemistry, vol. 29, pp. 1702-1706, 1957.

[24] T. Akahira and T. Sunose, "Method of determining activation deterioration constant of electrical insulating materials," Research Report of Chiba Institute of Technology, vol. 16, pp. 22-31, 1971.

[25] T. Ozawa, "Kinetic analysis of derive curves in thermal analysis," Journal of Thermal Analysis, vol.2, pp. 301-324, 1970.

[26] J. H. Flynn, "The 'Temperature Integral'-Its use and abuse," Thermocbimica Acta, vol. 300, pp. 83-92, 1997.

[27] C. D. Doyle, "Series approximations to the equations of thermogravimetric data," Nature, vol. 207, pp. 290-291, 1965.

[28] C.-P. Lin, Y.-M. Chang, J. P. Gupta, and C.-M. Shu, "Comparisons of TGA and DSC approaches to evaluate nitrocellulose thermal degradation energy and stabilizer efficiencies," Process Safety and Environmental Protection, vol.88, pp. 413-419, 2010.

[29] V. Pasangulapati, K. D. Ramachandriya, A. Kumar, M. R. Wilkins, C. L. Jones, and R. L. Huhnke, "Effects of cellulose, hemicellulose and lignin on thermochemical conversion characteristics of the selected biomass," Bioresource Technology, vol.114, pp. 663-669, 2012.

[30] T. Faravelli, A. Frassoldati, G. Migliavacca, and E. Ranzi, "Detailed kinetic modeling of the thermal degradation of lignins," Biomass and Bioenergy, vol.34, pp. 290-301, 2010. 
